\title{
Does CVS-Aetna Spell the End of Business as Usual?
}

\section{Citation}

Dafny, Leemore S. "Does CVS-Aetna Spell the End of Business as Usual?" The New England Journal of Medicine 378, no. 7 (2018): 593-95.

\section{Permanent link}

http://nrs.harvard.edu/urn-3:HUL.InstRepos:39061565

\section{Terms of Use}

This article was downloaded from Harvard University's DASH repository, and is made available under the terms and conditions applicable to Other Posted Material, as set forth at http:// nrs.harvard.edu/urn-3:HUL.InstRepos:dash.current.terms-of-use\#LAA

\section{Share Your Story}

The Harvard community has made this article openly available.

Please share how this access benefits you. Submit a story.

\section{Accessibility}



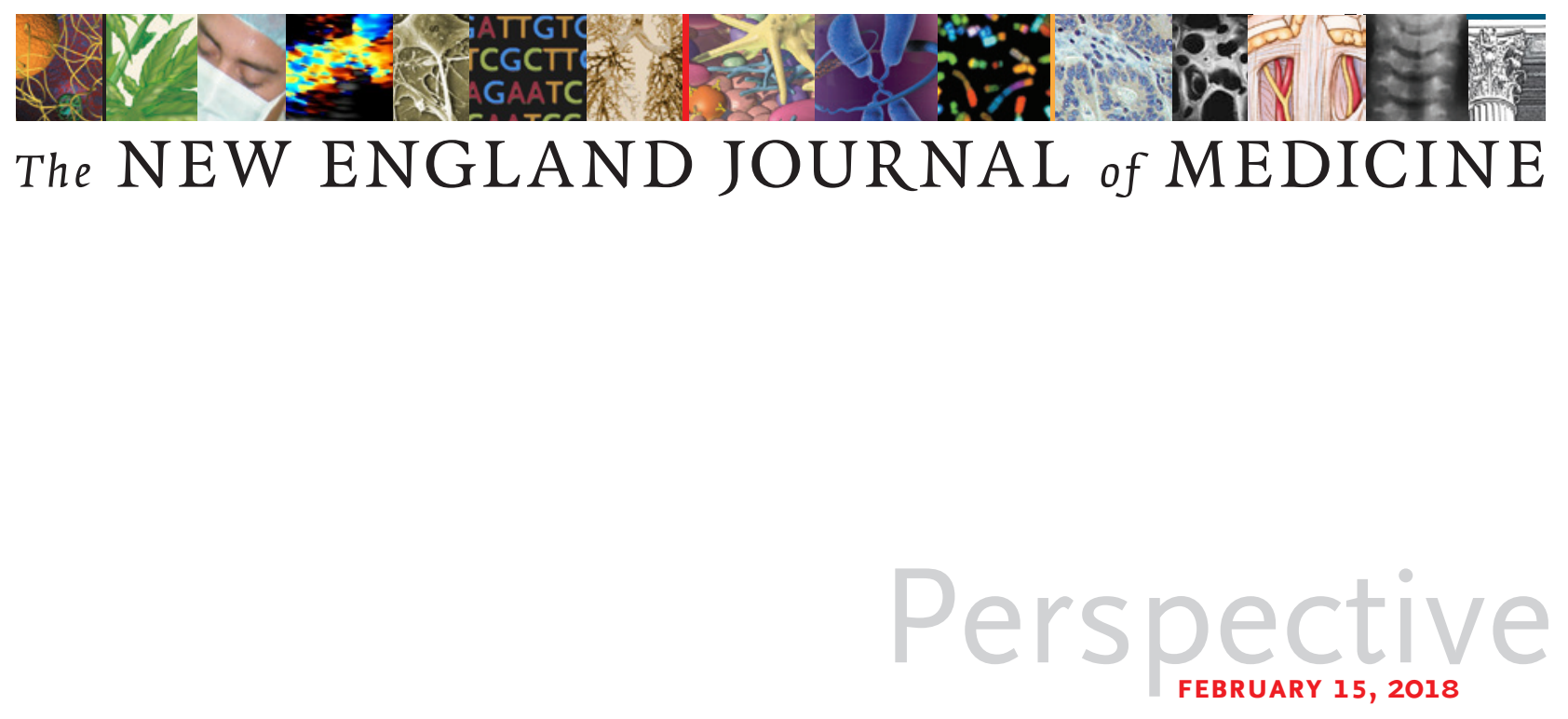

\title{
Does CVS-Aetna Spell the End of Business as Usual?
}

\author{
Leemore S. Dafny, Ph.D.
}

nother day, another mega-deal - or so it
seems. But the proposed $\$ 70$ billion merger
of CVS and Aetna would be the largest deal

company mergers and among the 20 largest deals in history. So this seems an appropriate occasion to pause and consider what it might mean for the health care delivery system.

The new company (let's call it NewCo) combines a health insurer (Aetna) with a pharmacy benefit manager (PBM; CVS Caremark) and a retail pharmacy and provider chain (CVS stores and Minute Clinics). Unlike other recent health care mega-deals, the proposed arrangement is not about one firm gobbling up another that provides essentially the same services, often in the same geographic markets. Those "horizontal" mergers can pose clear competition and antitrust concerns. Indeed, Aetna's last proposed deal (with rival Humana) was blocked by the U.S. Department of Justice.

The proposed CVS-Aetna merger is largely "vertical," involving consolidation "up and down" the value chain (see diagram). Vertical mergers enable myriad channels that can actually heighten competition, although there is still a risk that competition will be lessened at some point in the value chain.

How might NewCo heighten competition for patients, offering them greater value for their money? It aims to be a "new front door to health care in America," aggressively expanding the scope of services supplied in its in-store Minute Clinics. This statement understandably set off alarms for provider organizations. Whenever an insurer merges with a provider, the logical expectation is that the new entity will try to change or expand the provider's business, potentially at the expense of rivals.

Currently, Minute Clinics provide a limited array of mostly acute care services, at prices below those of outpatient clinics, urgent care facilities, and certainly emergency departments (EDs). Episodes of care originating at retail clinics might also be cheaper if they entail fewer referrals for additional care, and that additional care doesn't generate benefits that exceed costs. Nonetheless, the jury is still out on whether retail clinics reduce even short-term health care spending: a recent study of 1.3 million Aetna enrollees found that retail clinics' convenience leads to greater use, more than offsetting savings from lower prices. ${ }^{1}$

CVS is plunging ahead nonetheless, and it's easy to see why. It's facing an onslaught of e-tailers 


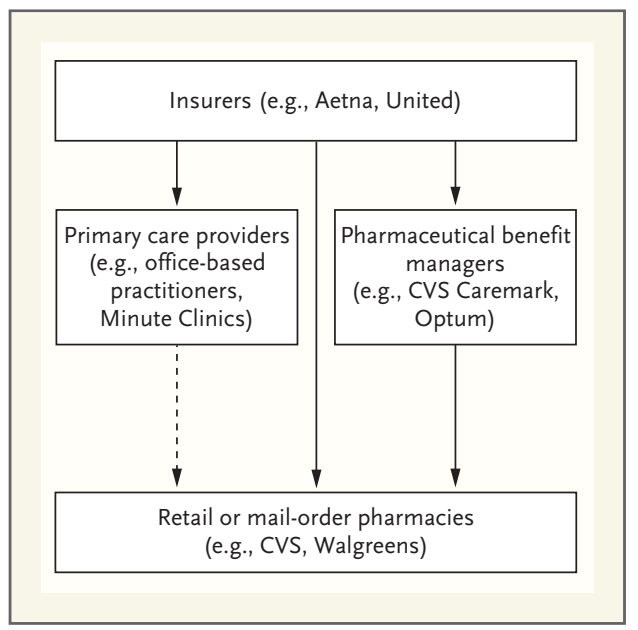

Simplified Chain of Production for Primary Care Services Generating Retail Prescriptions.

Solid arrows indicate contractual relationships or ownership, and the dashed arrow indicates referral for prescription.

- particularly Amazon - siphoning revenues from front-of-store sales and threatening to enter the lucrative prescription-drugdelivery market. Amazon provides a seamless shopping experience for other consumer goods, and though drugs are a more complex market than books or electronics, Amazon has revolutionized the buying experience and forced traditional brick-and-mortar retailers to either up their game or fold.

To avoid going the way of Blockbuster (the video-rental chain store that closed when mail video delivery arrived and streaming was in the offing), CVS and other drugstores need to take this threat seriously by keeping their real estate front and center in the health care ecosystem. If you don't need to visit your CVS to grab your prescription or toilet paper, how about to check your blood pressure, monitor your diabetes, or have a technicianassisted video visit with a specialist? To stay relevant, CVS intends to offer a different value proposition to patients. For this effort to pay off, that proposition must be better than what existing providers currently offer - or will ultimately offer to combat the new competition. Either way, patients win.

With a focus on total costs of care in Aetna's corporate DNA, NewCo will aspire to reduce total spending for care (while increasing its own revenues) by redirecting patients to lower-cost sites for certain services, such as infusions or imaging (in which NewCo may have ownership stakes); using its physical convenience and nonvisit care technologies to maintain contact with patients requiring closer monitoring, thereby potentially averting ED visits and admissions; and considering combined medical and pharmacy spending.

Aetna can directly support these objectives by encouraging members to use Minute Clinics, other NewCo-affiliated providers, CVS pharmacies, and Caremark services - perhaps through favorable cost sharing or more seamless scheduling, billing, and care or product delivery. To the extent that CVS's physical and digital efforts can lower total costs of care, NewCo can benefit directly from anyone insured by Aetna, and indirectly by sharing in savings with members of selfinsured plans. Notably, Aetna is building market share in Medicare Advantage plans, and arguably Medicare Advantage enrollees are the members most likely to appreciate and benefit from frequent, high-touch interactions with CVS pharmacists and nurse practitioners.

The integration of medical and prescription-drug insurance may also yield total cost savings and better health. Medicare Advantage plans with Part D prescription-drug benefits tend to spend more than standalone, prescription drug-only Part D plans on drugs that are likely to generate offsetting reductions in medical spending. ${ }^{2}$ Relatedly, NewCo might have greater financial incentives than separate medical insurers and PBMs to invest in medication adherence that improves health and reduces total costs.

How much consumers stand to benefit - or lose - as a result of this transaction depends on whether these and other potential savings are realized and passed through to consumers, and also on the long-term effects on competition.

One concern antitrust enforcers are likely to evaluate is whether CVS-Aetna could "foreclose" rivals, say by refusing to offer PBM services to other insurers or declining contracts to fill prescriptions for other insurers' enrollees - perhaps in geographic areas where Aetna wishes to defend or strengthen its market share. Another possible concern is that in the absence of a merger, Aetna could have been a "potential entrant" in some business segments in which CVS currently operates, such as pharmaceutical benefit management. Its rival United, after all, has a large and successful PBM subsidiary.

So if the deal closes, does it mean the eventual end of business as usual? Some industry participants will argue that retail clinics are, and will remain, a minor part of the health care value chain. Patients are loyal to their primary care providers, and clinics that don't offer the same scope of care will primarily han- 
dle minor ailments, maybe checking blood pressure and hemoglobin levels occasionally. After all, the retail clinic chains have been saying for years that they will expand significantly into chronic care management; if the value were so compelling (or access to new patients so likely), that should have happened already. Insurers could have created joint ventures with retail clinics or benefit designs that more strongly encouraged use of those clinics. The fact that they haven't could indicate that clinics have less potential than the framers of NewCo claim. Providers can return to business as usual.

The less cynical might observe that health care is ripe for change, and NewCo is well positioned to capitalize on the demand for that change. Patients are now accustomed to highquality, digitally enabled services and are growing weary of the antiquated way they access primary care. It's hard to park at the doctor's office, one still can't usually book an appointment online, the wait is impossible to predict, and those are just tips of the iceberg of health care dysfunction. Seamless communication among insurers, pharmacies, and prescribers would save a lot of time and misery. Some of the healthiest and most profitable patients might gladly embrace CVS as a primary care provider, particularly if they're offered lower copayments and easy scheduling.

I would argue that providers' reaction should be the same whether they believe CVS-Aetna is a game changer or merely a pocket liner for executives and their advisors. The battle to take medical risk for patients and to manage and deliver the products and services they require is heating up. If CVS-Aetna cannot lure patients away with lower prices and convenient services, some other player will surely try.

Providers will have to figure out how to provide better, more convenient, less costly care - to offer the best affordable pathway to good health. They can choose to team up with NewCo if they believe total cost and quality of care will be improved that way, or work with other insurers to design products that minimize interactions with NewCo if they believe otherwise.

Competition can cut both ways for providers, but as long as it's not diminished by this megadeal - a question to be sorted out by antitrust investigators patients stand to gain. Let the games begin.

Disclosure forms provided by the author are available at NEJM.org.

From the Department of General Management, Harvard Business School, Boston, and the Kennedy School of Government, Harvard University, and the National Bureau of Economic Research, Cambridge all in Massachusetts.

1. Ashwood JS, Gaynor M, Setodji CM, Reid RO, Weber E, Mehrotra A. Retail clinic visits for low-acuity conditions increase utilization and spending. Health Aff (Millwood) 2016;35:449-55.

2. Starc A, Town RJ. Internalizing behavioral externalities: benefit integration in health insurance. NBER working paper No. 21783. Cambridge, MA: National Bureau of Economic Research, December 2015 (http:// www.nber.org/papers/w21783).

DOI: 10.1056/NEJMp1717137

Copyright (๑) 2018 Massachusetts Medical Society.

\section{Medical Devices in the Real World}

Frederic S. Resnic, M.D., and Michael E. Matheny, M.D., M.P.H.

W hen it comes to medical devices, the Food and Drug Administration (FDA) is tasked with the herculean balancing act of ensuring efficacy and safety while accelerating access to new technologies for patients most likely to benefit from them. These two goals are inherently in conflict, but the FDA must make decisions daily, with imperfect information, regarding the approval and continued use of devices.
The approval process has been criticized for being burdensome and slow, and new medical devices are frequently available for use outside the United States well before FDA review and clearance occur. Yet the FDA has also been criticized for inadequate evaluation of medical devices, and there have been notable recalls due to serious and occasionally fatal consequences of device failures. Further challenging this balanc- ing act is the dynamic nature of medical devices, which, unlike drugs, undergo continuous iteration and design improvements.

The recently passed 21st Century Cures Act provides guidance in balancing these competing priorities by directing the FDA to consider how best to use realworld evidence (RWE) for reasonable assurance of device safety and effectiveness while accelerating access to important new tech- 